\title{
Formação continuada de professores ao incluir aluno surdo no ensino superior: relato de experiências
}

Continuing teacher education to include deaf student in higher education: experiences report

Formación continuada de profesores al incluir alumno sordo a la enseñanza superior: relato de experiencias

TEREZINHA RICHARTZ (D)a

THIAGO LEMES DE OLIVEIRA (Da

\section{Resumo}

Em uma sociedade diversificada e cada vez mais preocupada com a equidade humana, compete ao professor uma atualização constante de seus conhecimentos, e consequentemente, ressignificação didática. Objetiva-se, neste artigo, portanto, discutir a importância da formação continuada de professores face à inclusão de um aluno surdo em sala de aula, em um curso de Pedagogia no interior de Minas Gerais, bem como, apresentar o gênero autobiográfico para se conhecer o contexto histórico do discente no intuito de identificar e desenvolver metodologias que promovam sua interação e mediação. Destina-se, ainda, relatar a experiência vivenciada por todos os sujeitos envolvidos na busca de alternativas de mediação, ensino, avaliação e por último, descrever as adaptações realizadas para respeitar a singularidade linguística do discente Surdo. A partir dessa perspectiva, o referencial teórico se pauta em autores como, Frison; Simão, Oliveira, Nacarato, Nóvoa e Foucault. A metodologia utilizada configura o relato de experiência associada à autobiografia de um aluno Surdo. Como resultado, observa-se que a formação continuada, atrelada ao trabalho em conjunto de professores e tradutor e intérprete de Libras, foi fundamental para entender demandas apresentadas a

\footnotetext{
a Grupo Unis, Varginha, MG, Brasil. Doutora em Ciências Sociais, e-mail: terezinha.richartz@professor.unis.edu.br

a Universidade Federal de Uberlândia (UFU), Uberlândia, MG, Brasil. Mestre em Educação, e-mail: thilemesoli@gmail.com
} 
partir da especificidade do aluno surdo, além de compartilhar ações práticas e vivências de seus participantes durante esse processo.

Palavras-chave: Formação continuada de professores. Inclusão. Aluno surdo.

\begin{abstract}
In a diversified society and increasingly concerned with the human equity, it is up to the teacher constantly update his knowledge, and consequently didact reframing. This article aims to discuss the importance of continuing teacher education to include one deaf student in classroom space, in a Pedagogy course in the interior of Minas Gerais state, whilst presents the autobiographical genre to know the historical context of the student, in order to identify and develop methodologies that involve interaction and mediation. Aims, still, report the experience lived by all the people involved in the search for mediation alternatives, teaching, assessment, and finally, describe the adaptations developed to respect the linguistic singularity of the deaf student. From this perspective, the theoretical framework is based on authors such as Frison, Simão, Oliveira, Nacarato, Nóvoa and Foucault. The methodology used configures the experience report associated with the autobiography of a deaf student. As a result, it is observed that continuing teacher education linked is work together with teachers and interpreter of Libras was fundamental to understand the needs presented from the specificity of the deaf student, besides to sharing the practical actions and experiences of this participants during this process.
\end{abstract}

Keywords: Continuing teacher education. Inclusion. Deaf student.

\title{
Resumen
}

En una sociedad diversificada y cada vez más preocupada con la equidad humana, compete al profesor una actualización constante de sus conocimientos, y consecuentemente, una resignificación didáctica. Se objetiva, en este artículo, por lo tanto, discutir la importancia de la formación continuada de profesores ante la inclusión de un alumno sordo en el aula, en un curso de Pedagogia en el interior de Minas Gerais, así como presentar el género autobiográfico para que conozca el contexto histórico del discente con intuito de identificar y desarrollar metodologías que fomenten su interacción y mediación. Se destina aún, relatar la experiencia vivida por todos los sujetos involucrados en la búsqueda de alternativas de mediación, enseñanza, evaluación y por último, describir las adaptaciones realizadas para respetar la singularidad lingüística del discente sordo. A partir de esa perspectiva, el referencial teórico está basado en autores como, Frison, Simão, Oliveira, Nacarato, Nóvia y Foucault. La metodología utilizada configura el relato de experiencia asociada a la autobiografía de un alumno sordo. Como resultado, se observa que la formación continuada, relacionada al trabajo conjunto de profesores y traductor interprete de Libras, fue fundamental para entender demandas 
presentadas a partir de las especificidades del alumno sordo, aparte de compartir acciones prácticas y vivencias de sus participantes durante ese proceso.

Palabras clave: Formación continuada de profesores. Alumno sordo. Inclusión.

\section{Introdução}

A presente pesquisa compartilha a experiência transformadora de uma comunidade acadêmica, ao acolher e incluir um aluno Surdo em um curso de Pedagogia no interior do estado de Minas Gerais. Ecoam, nas páginas a seguir, as reflexões, depoimentos, adaptações metodológicas e ressignificações práticas de alunos, professores e tradutores e intérpretes de Libras que se constituem agentes dessa transformação. São, portanto, o corpus desse trabalho as narrativas autobiográficas e relatos de experiência. A pesquisa autobiográfica se fez relevante, pois, além dos autores, demais agentes educacionais interessados poderão identificarse e repensar sua prática bem como sua própria aprendizagem. Este formato de pesquisa tem se popularizado, já que permite, tanto ao autor como ao leitor, estabelecer um diálogo favorável para a construção de novos saberes. A pesquisa narrativa autobiográfica é aquela que conta ao leitor um recorte de fatos ou situações vividas pelo autor, com a intencionalidade de motivar, sensibilizar, expor, provocar suas concepções e crenças acerca do problema.

O uso das narrativas autobiográficas, atualmente, expande-se como tendência na formação de professores, mais especificamente na identificação das influências que conduziram e conduzem o sujeito à docência, sendo também uma subárea em constante expansão da Linguística Aplicada. No âmbito nacional, essa tendência é evidenciada, por exemplo, nas pesquisas de Frison e Simão (2011) que discutem o elo entre narrativas (auto)biográficas e aprendizagem autorregulada, no processo de formação de professores em cursos de Pedagogia no Brasil e de Educação Básica em Portugal. Oliveira (2011) reflete sobre como as narrativas permitem o estudo de aspectos como a construção da identidade docente, ao contar sua história para apropriar-se dela em um processo, eminentemente formativo, de autoria, durante a formação inicial e continuada. Já em Nacarato (2015), as narrativas são ferramentas 
utilizadas para compreender a (re)constituição de sentidos que estudantes e professores de matemática dão às suas trajetórias de formação e vida profissional. Oliveira (2017) ressalta que, ao recontar as histórias de sua vida escolar, rememorar acontecimentos e pessoas, e tornar-se leitor delas, muda-se a concepção do que é ser professor, compreendendo sua própria identidade docente como professor de Língua Portuguesa.

Nesse viés, essa pesquisa assemelha-se às anteriores resenhadas, por balizar-se em autobiografias de estudantes e professores de uma licenciatura que investigam a constituição de sua identidade pessoal e profissional. Entretanto, distingue-se por refletir sobre como as identidades dos seus pares influenciam a sua própria durante o processo formativo contínuo, ressignificando sua prática e postura docentes. Mais especificamente, discute como o ingresso de um aluno surdo em um curso de Pedagogia transformou toda uma comunidade acadêmica.

Com isso, convém preambular acerca do aluno surdo e do porquê o seu ingresso marcou a forma da instituição e da comunidade acadêmica pensar a sua inclusão e de futuros alunos Surdos, conforme será apresentado posteriormente na metodologia. O aluno ingressou no Ensino Superior aos 23 anos, surdo de nascença por causas não detectadas, em uma pequena cidade do interior de Minas Gerais. Filho de pais trabalhadores rurais, sem formação escolar, com conhecimento limitado da Língua Portuguesa e nenhum conhecimento de Libras, houve dificuldade em relação ao seu acesso à educação com a mesma equidade de seus colegas ouvintes.

Ao ingressar na instituição, estava munido apenas de um forte desejo por uma vida diferente daquela vivida por seus pais, trabalhando na "panha de café", para custear sua educação superior. Entretanto, seu conhecimento, tanto da Língua Portuguesa quanto da Libras não era compatível com a linguagem acadêmica, mobilizando professores, tradutores e intérpretes, alunos e demais agentes educacionais a sanar o problema e incluir tal aluno, a partir dos seguintes questionamentos que constituem os norteadores desse trabalho: (a) Quais são a necessidades do aluno e como poderiam ser abordadas? (b) Em que professores, alunos e agentes educacionais poderiam contribuir para a inclusão do aluno? (c) Em relação ao material, conteúdo e metodologia de ensino, poderiam ser adaptadas para o aluno respeitando suas limitações e potencializando seus saberes? 
A fim de responder a tais questionamentos, o presente artigo foi organizado da seguinte forma: no subtópico "A formação continuada para a prática pedagógica”, serão apresentadas as reflexões de pesquisadores da área, apontando a formação continuada de professores como estratégia fundamental para ressignificar a prática docente. Já em "Uma inclusão em etapas" será caracterizada a abordagem metodológica dessa pesquisa, na medida em que se narram as ações realizadas para incluir o aluno surdo e, consequentemente, promove-se a formação continuada de professores, tradutor e intérprete e demais agentes educacionais. Em “Aprender a aprender: a experiência do TCC”, são narradas por seu orientador e coorientador, autores deste trabalho, as etapas práticas que permitiram ao aluno produzir seu Trabalho de Conclusão de Curso. Por fim, em "Considerações finais", serão expressas as contribuições dessa pesquisa para seus autores, leitores e comunidade acadêmica.

\section{A formação continuada para a prática pedagógica}

No ano de 2002, através da Lei no 10.436/02, o Brasil reconhece a Língua de Sinais Brasileira - Libras - como segunda língua. Já em 2005, a partir do Decreto $\mathrm{n}^{\circ} 5.626 / 05$, assegura-se a inclusão de alunos surdos ou com deficiência auditiva no ensino regular. Com essas normativas, portanto, as escolas começam a recebê-los. Porém, segundo a Cartilha do Censo 2010, sobre pessoas com deficiência, o índice em referência corresponde a 5,10\% da população, (BRASIL, 2012) e deste, apenas 7\% têm Ensino Superior completo (GANDRA, 2019), o que identifica, a partir destes dados, problemas graves em relação à inclusão, já que a maioria dos alunos surdos não progridem na vida acadêmica.

Hoje a legislação é clara sobre a necessidade de incluir alunos com deficiência auditiva na rede regular de ensino, mas a maior dificuldade está no professor. Grande parte não tem preparação adequada para lidar com alunos surdos. Como não existe material que englobe todas as especificidades de cada sujeito, é necessário se debruçar sobre a singularidade de cada um e, além da Língua Brasileira de Sinais — que já é um direito - , buscar alternativas metodológicas para que este indivíduo possa aprender.

Logo, o aluno surdo passa a ter direito a acessar os conteúdos curriculares na sua primeira língua — Libras e, quando essa comunicação não é garantida pelo seu 
professor, surge o tradutor e intérprete de Libras (BRASIL, 2010) como mediador do processo ensino-aprendizagem. Para tanto, a necessidade de formação continuada dos professores tem maior visibilidade com as mudanças sobre o entendimento dos direitos da pessoa com deficiência, porque em cada período se tem um discurso vigente. Aponta-se que, enquanto, a inclusão não era lei, a formação continuada não tinha a prioridade que tem agora.

Segundo Foucault, o conceito de prática discursiva refere-se a um: “[...] conjunto de regras anônimas, históricas, sempre determinadas no tempo e no espaço, que definiram, em uma dada época e para uma determinada área social, econômica, geográfica ou linguística, as condições de exercício da função enunciativa" (FOUCAULT, 2008, p. 136). O discurso é prática, é ação. A linguagem não apenas nomeia o mundo, mas o constrói.

Nesta perspectiva, para pensar a inclusão deve-se considerar o discurso presente no contexto em que a deficiência é pensada e, concretamente, onde o deficiente está inserido. Assim, os discursos que permeiam a prática pedagógica são pensados a partir do que se entende por pessoa com deficiência. Hoje ele é um sujeito de direito e, como tal, deve ser incluído. No entanto, ainda coexiste o discurso da deficiência como doença e essa deve ser tratada e preferencialmente curada. E, se a cura não for possível, a pessoa com deficiência deve ser encaminhada para escolas especializadas.

Esse é um discurso que, embora ultrapassado, não foi ainda superado. É possível perceber, nas instituições de ensino, certo estranhamento de alguns profissionais em relação à necessidade de se adaptar toda a forma de ensinar porque estão agarrados aos velhos manuais pedagógicos. As receitas prontas precisam ser jogadas fora e a prática deve ser ressignificada com muito estudo, debate e observação da realidade.

Essa interação com o aluno surdo é imprescindível para o professor levantar, a partir da subjetividade do discente com deficiência auditiva, o que, na prática pedagógica, pode facilitar o processo de ensino-aprendizagem. Nesse contexto, o professor precisa se adaptar às particularidades de cada aluno surdo: há os que fazem leitura labial, os que ouvem um pouco com ajuda de aparelho e os que são completamente surdos. Isso mostra que aulas prontas e metodologias usuais não 
fazem mais sentido. Deve-se analisar precisamente cada caso para se traçar práticas pedagógicas direcionadas e adequadas a cada um deles. Por isso, defende-se "[...] a necessidade de uma formação centrada nas práticas e na análise dessas práticas” (NÓVOA, 2007, p. 14); o que pode funcionar com um discente, mas não necessariamente pode ser aplicado em outra realidade. Nesse sentido, cabe ao professor estudar e partilhar com os demais profissionais da área alternativas que possam ser promissoras em cada situação.

Observa-se, portanto, a importância da formação continuada quanto à ressignificação da prática pedagógica a partir das novas subjetividades que estão aparecendo na sala de aula. Nóvoa afirma em evento no Brasil, que a reflexão sobre a experiência e a prática formam o docente: "Educar não é uma atividade transmissora, mas de criatividade. Educação é uma espiral interminável. Não se conclui a formação, ela é contínua" (FUNDAÇÃO CAPES, 2014, p. 1). Dessa forma, quando o docente recebe um aluno surdo, precisa entender como funciona o seu processo de aprendizagem e, por isso, precisa ouvi-lo. Sobre isso, ecoam as palavras de Quadros ao dizer que:

O surdo se vê como uma diferença (Como um sujeito que reivindica seus espaços, os quais existem independentemente de autorização ou aceitação por quem quer que seja), uma diferença entre tantas outras diferenças como, por exemplo, o 'Ser ouvinte' - que, na perspectiva do surdo, na sua tradução mais radical das formas de representação, significa ser incapaz de compreender o seu mundo o mundo visual (QUADROS, 2003, p. 94).

Esse momento é muito significativo para tradutores e intérpretes de Libras pelo fato de contribuírem com o professor, a partir de uma avaliação diagnóstica, para entender as necessidades e resolvê-las. Estimula-se, assim, o profissional, à reflexão e à busca de alternativas metodológicas para trabalhar alunos que possuem particularidades linguísticas, visto que, por meio destas, as estratégias pedagógicas são traçadas. Em verdade, a surdez, como diferença e não como deficiência, enfatiza a singularidade da pessoa e não o fato de ela não ouvir. Daí a necessidade de se entender como esse sujeito aprende. Para Antônio Nóvoa (1991), a escola é o espaço de formação continuada do educador. Em uma relação dialética entre desempenho profissional e aprimoramento da sua formação, aprende-se, desaprende-se, estruturam-se e descobrem-se novos aprendizados, sistematizam-se novas posturas 
nas suas "práxis". Mas a formação continuada só tem credibilidade se os programas de formação forem montados em torno de problemas e de projetos de ação e não em torno de conteúdos acadêmicos (NÓVOA, 1991, p. 30).

Serra (2006, p. 34) observa que demanda da inclusão tem chegado às escolas antes da preparação do professor, o que evidencia que a solução tem sido a capacitação do profissional em serviço, através de programas de formação continuada. Para ratificar essa compreensão, Nóvoa afirma: “A formação continuada deve alicerçar-se numa reflexão na prática e sobre a prática, através de dinâmicas de investigação-ação e de investigação-formação, valorizando os saberes de que os professores são portadores” (NÓVOA, 1991, p. 30). A formação escolar deve, então, articular-se com o cotidiano.

Nessa conjectura, o próximo tópico caracteriza a abordagem metodológica dessa pesquisa, ao passo que narra as adaptações pedagógicas que foram desenvolvidas, a fim de incluir o aluno surdo, respeitando suas particularidades linguísticas, bem como sua singularidade cultural.

\section{Uma inclusão em etapas}

O trabalho aqui descrito é de abordagem qualitativa e, como mencionado anteriormente, ancora-se nas teorias de formação de professores, balizando-se no uso de narrativas autobiográficas, oral e escrita, como ferramenta para repensar e ressignificar a prática docente. Mais especificamente, apoia-se na formação continuada como uma estratégia formativa de refletir sobre a prática em meio à investigação e valorização de seus envolvidos (NÓVOA, 1991). Com essa premissa, retomando o preâmbulo, na introdução deste artigo, vale ressaltar que, para compreender a necessidade das etapas realizadas para incluir o aluno surdo, um dos sujeitos dessa pesquisa, fez-se necessário o uso de excertos de sua autobiografia, parte de seu trabalho de conclusão de curso, aprovado em 25/04/2019 pela comissão avaliadora e disponível na biblioteca da instituição. Por isso, os excertos aqui utilizados encontram-se escritos em itálico, para fins de identificação.

Respondendo a primeira pergunta dessa pesquisa sobre quais eram as necessidades do aluno e como poderiam ser abordadas, evidentemente, a primeira 
preocupação atrelou-se ao fato de a língua de instrução do curso, a saber, a Língua Portuguesa, ser a segunda língua do aluno. De acordo com Brito (2019, p. 16):

Sendo surdo, me via sempre sozinho e sentia a necessidade de aprender o português para me comunicar melhor com os ouvintes. Essa ainda é a realidade de muitos surdos no interior de Minas Gerais, alguns inclusive fazem parte do meu grupo de amigos. A dificuldade em realizar esse desejo, em grande parte, ainda se deve à falta de intérpretes qualificados para mediar as relações e/ou contato com os ouvintes. A dificuldade também ocorria pelo uso e entendimento do português.

Esse é um problema recorrente e característico na vida das crianças surdas, conforme apontam Karnopp e Pereira:

[...] pelo fato de vir de famílias ouvintes, a maior parte das crianças surdas, embora cheguem à escola com uma linguagem, constituída na interação com as mães ouvintes, não apresenta uma língua na qual possa se basear na tarefa de ler e a escrever. Assim, sem uma língua constituída, a criança surda inicia o seu processo de alfabetização, o que ainda na maioria das escolas, se dá por meio do ensino de vocábulos, combinados em frases descontextualizadas. O distanciamento das práticas de leitura e de escrita, somado a pouca ou nenhuma familiaridade com o português, resulta em alunos que sabem codificar e decodificar os símbolos gráficos, mas que não conseguem atribuir sentido ao que leem (2015. p. 35).

Desta forma, para que a inclusão do aluno surdo ocorresse de forma efetiva, atendendo às suas necessidades, a primeira etapa de inclusão contou com a contratação de um tradutor e intérprete de Libras com formação superior no mesmo curso em que o aluno estava matriculado.

De acordo com Brito (2019, p. 16-17):

Muitas vezes, por falta de acompanhamento, os surdos não compreendem as palavras, vemos as letras como símbolos sem sentido, pois, para nós, a Libras é nossa primeira língua (L1) e língua natural, ao passo que o português é nossa segunda língua (L2). Essa dificuldade se agrava quando não temos o acompanhamento e as adaptações em atividades escolares necessárias para nosso aprendizado. Nesse momento, a figura do tradutor e intérprete de Libras é essencial, conforme apresentam Lemes e Figueiredo:

Quando se trata da produção escrita do sujeito surdo, o tradutor e intérprete constitui-se também uma ferramenta de inferência essencial para aproximar o leitor a ideia do autor. Isso ocorre, pois, esse profissional é o responsável por auxiliar na atribuição da coerência e coesão da produção textual escrita ou sinalizada do autor, tendo em vista que ele é dotado dos recursos linguísticos necessários para organizar a transferência textual de uma língua para outra considerando a formação cultural e constituição social do autor (2019, p. 43). 
Logo após sua contratação, o tradutor e intérprete de Libras, também pedagogo, realizou uma avaliação diagnóstica, apresentando o perfil do aluno Surdo aos seus professores, durante uma reunião pedagógica. Com isso, foram programadas ações para que o resgate educacional e a formação do aluno fossem desenvolvidos respeitando sua singularidade cultural e linguística. A primeira ação consistiu na compreensão da gramática da Libras, de sua escrita da Língua Portuguesa, e na instauração de aulas de reforço antes do horário de aula realizadas por uma professora da disciplina de "Alfabetização e Letramento", mediadas pelo tradutor e intérprete de Libras. Nas aulas de reforço eram utilizados os conteúdos das disciplinas cursadas pelo aluno naquele momento.

Para a segunda ação inclusiva, foi produzido e ofertado um curso introdutório de Libras com carga horária de 20 horas/aulas para demais agentes educacionais e administrativos, a fim de que o aluno Surdo tivesse autonomia na comunicação nos demais setores da universidade. O curso foi realizado no segundo semestre de 2017 e contou com 18 participantes. Dentre esses, estavam profissionais de atendimento (secretarias e central de aluno), bibliotecários, porteiros, auxiliares administrativos, auxiliares de limpeza e tutores pedagógicos.

Após a capacitação e conscientização de pessoas, foi necessária uma adaptação de materiais, métodos de ensino, apresentação de trabalhos e formatos de trabalhos realizados pelo aluno a fim de atender as suas necessidades. Um exemplo dessas adaptações pode ser observado nas imagens a seguir, que apresentam uma questão adaptada em uma avaliação, para que o aluno tivesse autonomia em sua realização. 
Figura 1 - Questão de Fundamentos da Educação em avaliação final

19) Questão:(Valor:0,5 ponto). Na abordagem tradicional, o ensino é baseado em ensaio e erro, na pesquisa, na investigação, e cabe ao professor criar situaçōes, evitar rotina, ele deve propôs problemas, sem dar-lhes as soluções.

Diante da afirmativa acima, assinale a alternativa correspondente:

\begin{tabular}{|l|l|l|}
\hline a) & ( ) & Abordagem Sociocultural. \\
\hline b) & ( ) & Abordagem Cognitivista. \\
\hline c) & ( ) & Abordagem Comportamentalista. \\
\hline d) & ( ) & Abordagem Humanista. \\
\hline e) & ( ) & Abordagem Interacionista. \\
\hline
\end{tabular}

Fonte: Avaliação institucional, 3º período de pedagogia. 2017.

Figura 2 - Questão de Fundamentos da educação adaptada em avaliação final

19) Questão:(Valor:0,5 ponto). Abordagem tradicional, ensino, pesquisa, tentativa e erro, professor evita rotina, problema resolver, professor não dá resposta. Combina qual?

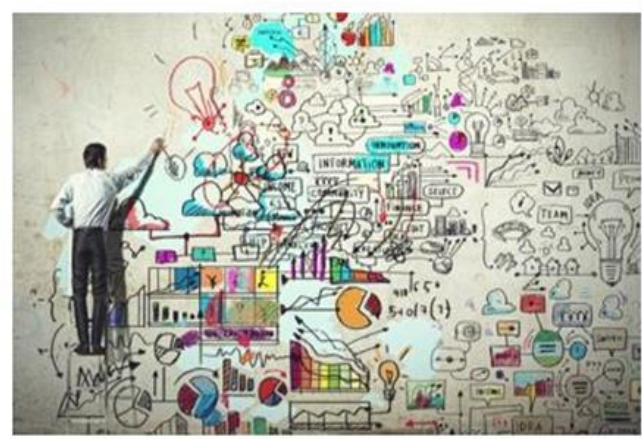

\begin{tabular}{|l|l|l|}
\hline a) & ( ) & Abordagem Sociocultural. \\
\hline b) & ( ) & Abordagem Cognitivista. \\
\hline c) & ( ) & Abordagem Comportamentalista. \\
\hline d) & ( ) & Abordagem Humanista. \\
\hline e) & ( ) & Abordagem Interacionista. \\
\hline
\end{tabular}

Fonte: Avaliação institucional adaptada, 3º período de pedagogia. 2017.

Nas imagens anteriormente expostas, nota-se que, a fim de conceder autonomia ao aluno surdo, o enunciado da questão foi reescrito com uma linguagem coloquial, sem omitir sua proposta de análise. Além disso, foi inserida uma imagem corroborando para a linguagem visual em que um professor propõe diferentes estratégias de ensino. Tais adaptações, demandadas pelo próprio aluno, permitiram que ele realizasse a avaliação, sem que o intérprete precisasse traduzir todos os enunciados e alternativas, atuando, nesse momento, apenas como apoio de sua comunicação com os aplicadores da avaliação e/ou professores. 
Por fim, após adaptar o material, conteúdo e metodologias de ensino, e respondendo à terceira questão desta pesquisa sobre como o material, conteúdo e metodologia de ensino poderiam ser adaptadas para o aluno respeitando suas limitações e potencializando seus saberes, a fim de resgatar os conhecimentos omitidos ao aluno devido a barreira linguística durante sua educação básica, o tradutor e intérprete de Libras, em parceria com seus professores, realizou um trabalho diário potencializando sua escrita acadêmica. A cada dia eram estudados cerca de dez verbetes da língua portuguesa a partir de sinais equivalentes na Libras. Tais verbetes deveriam ser utilizados em textos ou anotações do aluno e conferido/corrigido por seu intérprete e/ou professores. Tal ação, ao longo do curso, serviu para ampliar o vocabulário do aluno, bem como sua leitura e conhecimento de mundo, preparandoo para escrever seu Trabalho de Conclusão de Curso, como será apresentado a seguir.

\section{Aprender a aprender: a experiência do TCC}

A condução do TCC se fez a partir da interação e cooperação do discente surdo, do orientador e do tradutor e intérprete de Libras e, a este último, também coube a função de coorientador do trabalho. Decidiu-se, pois, fazer uma narrativa autobiográfica do processo de inserção escolar no ensino público mineiro (BRITO, 2019), logo, defendida, e portanto, pública.

Importa ressaltar a relevância desse processo pelo fato de poucos alunos surdos chegarem à posição de domínio das duas línguas: Libras e Português escrito. Em análise, todo o corpo docente e demais colegas de turma aprenderam muito sobre as dificuldades/facilidades de um aluno Surdo na escola regular.

Embora o professor orientador de conteúdo, e também professor de Metodologia Científica do curso não dominasse a língua de sinais, possibilitou orientação mediada continuamente pelo tradutor e intérprete de Libras, observandose, então, viabilidade quanto à interação para com o aluno surdo, visto que eram oferecidas a ele aulas coletivas, traduzidas em tempo real, sobre aspectos metodológicos na construção da monografia. Também foram feitos exercícios em sala de aula para treinar projeto de pesquisa, fichamento e regras da ABNT. 
A primeira etapa de elaboração do projeto de pesquisa foi a escolha do tema a ser estudado. Após apresentá-lo ao professor orientador e ao tradutor e intérprete de Libras que sugeriram/nortearam caminhos a serem observados e trilhados, o orientando se interessou em relatar, de forma autobiográfica, a sua inserção como aluno surdo em escolas regulares, para refletir sobre o processo de ensino/aprendizagem. O local de fala e as memórias de quem viveu a experiência de estar em escolas, em que os professores tinham formação precária na área da deficiência auditiva, nos pareceu rica. Este relato poderá sensibilizar quanto à necessidade da formação permanente, já que existem muitos fatores relacionados ao não domínio da Língua Brasileira de Sinais — Libras —, bem como a insuficiência de tradutores e intérpretes mediadores em sala de aula.

Embora existam diversos estudos durante o processo formativo em cursos de licenciatura, observa-se a importância de se relatar experiências vivenciadas com riqueza de detalhes, pelo pesquisador em seu Trabalho de Conclusão de Curso (TCC) pois podem contribuir para o real entendimento do assunto tanto para os já professores, quanto para os formandos em Pedagogia, que deverão lidar com os desafios da inclusão futuramente; visto que, ainda nos dias atuais é possível encontrar educadores com formação precária e, por esse motivo, não detêm conhecimento no que se refere à adaptação de material avaliativo, além de não conseguirem estabelecer o mínimo de comunicação entre os corpos docente e discente.

Após elaboração do projeto de pesquisa, o orientador e coorientador selecionaram bibliografia pertinente sobre a temática para o discente ler e fichar. Sua leitura era acompanhada pelo tradutor e intérprete de Libras para que a seleção das passagens mais significativas fosse possível. Com a leitura e o fichamento prontos, iniciou-se a escrita do trabalho, constantemente acompanhada pelos dois profissionais, e sempre escrito e reescrito na tentativa de melhorar a redação.

A modalidade linguística utilizada no TCC foi a escrita. Porém, a apropriação da língua portuguesa escrita se desenvolveu gradativamente. Nesse processo, o e-mail foi um grande aliado, especialmente do professor, pois, como o discente surdo foi praticamente alfabetizado durante o curso de Graduação em Pedagogia, a comunicação escrita durante o período extrassala, foi garantido através desta ferramenta tecnológica. Assim, textos eram disponibilizados para leitura e 
fichamento. Portanto, toda a produção monográfica, desde a escrita do projeto, fichamentos das leituras realizadas, escrita do TCC pelo discente, era corrigida e devolvida via e-mail, o que proporcionou rapidez na comunicação e registros de tudo o que foi feito e refeito.

O discente teve a oportunidade de apresentar o TCC com a mediação do tradutor e intérprete de Libras, num evento científico internacional organizado pela Instituição de Ensino em que estudou e em outro de grande porte realizado na cidade, constatando-se o seu grande desempenho nas apresentações e, apesar das restrições linguísticas do público, com a tradução realizada pelo intérprete, o debate evoluiu normalmente.

Outra adaptação que merece destaque durante a apresentação de TCC do aluno foi o uso de linguagem não verbal. Tendo em vista que a língua portuguesa é a segunda língua do aluno, e que se nortear por ela em um momento de exposição em que a pressão incita o nervosismo, foi permitido pela comissão de avaliadores, que o aluno explorasse o uso de diferentes ferramentas tecnológicas, imagens e símbolos para discorrer sua pesquisa. Corroborando com Sofiato (2016, p. 793-794) o uso de imagens na educação de surdos, na contemporaneidade, além de serem previstos por lei, são recorrentes e constitui-se um recurso democrático, uma vez que perpassa o tempo acompanhando tendências de cada sociedade.

Com isso, em termos práticos, a apresentação do aluno pautou-se em uma apresentação com slides, contendo inicialmente uma linha do tempo colorida para norteá-lo quanto aos momentos e tópicos de sua síntese. Assim, a cada slide a cor de fundo guiava o aluno dentro de sua pesquisa, de acordo com a linha temporal estabelecida. Além disso, sua apresentação utilizou de fotografias do acervo familiar, já que sua pesquisa era autobiográfica, intercaladas com figuras, símbolos, ícones e sinais (ilustrações de léxicos da Libras), e fotografias dos teóricos utilizados, para que pudesse rememorar e destacar as citações utilizadas.

Por conseguinte, como ainda são poucos os casos de alunos surdos no curso superior, especialmente os que concluem, e ainda, os que apresentam Trabalho de Conclusão de Curso, o que se observou foi a curiosidade dos demais discentes em relação à performance do aluno surdo na defesa do trabalho. Acredita-se que, muito além da superação das dificuldades enfrentadas pelo docente orientador para atender 
à diferença linguística de seu orientando, principalmente em se tratando de apropriação da língua portuguesa escrita, o ambiente acadêmico da instituição de ensino superior foi modificado pela presença e pelas demandas geradas para que as diferenças e singularidades fossem respeitadas.

\section{Considerações finais}

$\mathrm{Na}$ perspectiva da inclusão, não existem respostas prontas e nem mesmo caminhos certos ou errados. Da mesma forma, um texto escrito por três pessoas, a exemplo: professor, tradutor/intérprete de Libras e aluno Surdo não objetiva uma estrutura lexical uniforme.

O presente fragmento traz os percalços de quem aprende, desaprende, reaprende. É um caminho que se faz entrelaçando as demandas que aparecem cotidianamente. Logo, a formação continuada de professores tornou-se ainda mais necessária pelo cenário exigido, e a língua de sinais, que já é obrigatória no Curso de Pedagogia, tornou-se muito mais significativa para a turma e para o corpo docente. Nesta perspectiva, aprender a aprender é uma atitude indispensável, já que, através da interação humana, exercitam a comunicação diretamente na sala de aula com o colega de classe surdo.

Portanto, é preciso criar nas escolas processos coletivos de formação e reflexão em que todos os envolvidos possam discutir e propor sugestões e, para isso, podem ser aproveitadas as reuniões pedagógicas ou reuniões com uma demanda específica, como no caso de um aluno que tem direito a uma intervenção mais específica. Neste sentido, refletir sobre as práticas pedagógicas aplicadas, especialmente com outros professores, equipe pedagógica, intérpretes e a pessoa surda é um caminho importante para verificar as falhas, avanços e socializar as medidas adotadas que facilitam o ensino-aprendizagem.

\section{Referências}

BRASIL. Lei no 10.436, de 24 de abril de 2002. Dispõe sobre a Língua Brasileira de Sinais e dá outras providências. Diário Oficial da União, 25 abr. 2002. 
BRASIL. Decreto no 5.626, de 22 de dezembro de 2005. Regulamenta a Lei no 10.436 , de 24 de abril de 2002, que dispõe sobre a Língua Brasileira de Sinais - Libras, e o art. 18 da Lei no 10.098, de 19 de dezembro de 2000. Diário Oficial da União, 23 dez. 2005.

BRASIL. Casa Civil. Lei no 13.219 , de $1^{\circ}$ de setembro de 2010. Regulamenta a profissão do tradutor e intérprete da Língua Brasileira de Sinais- LIBRAS. Brasília, Casa Civil, 2010.

BRASIL. Secretaria de Direitos Humanos da Presidência da República. Cartilha do Censo 2010: Pessoas com Deficiência. Brasília, SDH-PR/SNPD, 2012.

BRITO, W. do N. A educação de alunos surdos no interior de Minas Gerais: reflexões de um exaluno. Varginha: Unis, 2019.

FOUCAULT, M. Arqueologia do saber. Trad. L. F. Baeta Neves. Rio de Janeiro: Forense Universitária, 2008.

FUNDAÇÃO CAPES. António Nóvoa fala sobre a profissão e a prática na formação de professores em Uberaba. 2014. Disponível em: https://www.capes.gov.br/36-noticias/6682-antonio-novoafala-sobre-a-profissao-e-a-pratica-na-formacao-de-professores-em-uberaba. Acesso em: 25 fev. 2020.

FRISON, L. M. B.; SIMÃO, A. M. da V. Abordagem (auto)biográfica - narrativas de formação e de autorregulação da aprendizagem reveladas em portfólios reflexivos. Educação, v. 34, n. 2, p. 198-206, 2011.

GANDRA, A. País tem 10,7 milhões de pessoas com deficiência auditiva, diz estudo. Agência Brasil, 13 out. 2019. Disponível em: https://agenciabrasil.ebc.com.br/geral/noticia/201910/brasil-tem-107-milhoes-de-deficientes-auditivos-diz-estudo. Acesso em: 03 mar. 2020.

KARNOPP, L. B.; PEREIRA, M. C. C. Concepções de leitura e escrita na educação de surdos. In: LODI, A. C. B.; HARRISON, K. M. P.; CAMPOS S. R. L. (Orgs.). Leitura e escrita no contexto da diversidade. Porto Alegre, Mediação, 2015. p. 125-133.

NACARATO, A. M. As narrativas de vida como fonte para a pesquisa autobiográfica em Educação Matemática. Perspectivas da Educação Matemática, v. 8, n. temático, p. 448-467, 2015.

NÓVOA, A. Concepções e práticas da formação contínua de professores: In: NÓVOA, A. (Org.). Formação contínua de professores: realidade e perspectivas. Aveiro: Universidade de Aveiro, 1991. p. 15-38.

NÓVOA, A. Desafios do professor no mundo contemporâneo. São Paulo: Sinpro, 2007. Disponível em: http://www.sinprosp.org.br/arquivos/novoa/livreto_novoa.pdf. Acesso em: 20 fev. 2020.

OLIVEIRA, R. M. M. A. Narrativas: contribuições para a formação de professores, para as práticas pedagógicas e para a pesquisa em educação. Educação Pública, v. 20, n. 43, p. 289-305, 2011.

OLIVEIRA, G. S. Conbecimento prático profissional e prático pessoal: experiencias que vivi/vivo são as histórias que me constituem professor. Orientadora: Dilma Maria de Mello. Dissertação (Mestrado em Estudos Linguísticos) - Programa de Pós-Graduação em Estudos Linguísticos, Universidade Federal de Uberlândia, Uberlândia, 2017. Disponível em: https://repositorio.ufu.br/bitstream/123456789/20764/1/ConhecimentoPraticoProfissio nal.pdf. Acesso em: 14 dez. 2019. 
OLIVEIRA, T. L. D; FIGUEIREDO, C. A. D. D. M. Coautoria ou tradução? A retextualização da escrita acadêmica de um graduando surdo à rumo produção de sentidos. Caleidoscópio: literatura e tradução, v. 3, n. 1, p. 37-51, 2019. Disponível em: http://periodicos.unb.br/index.php/caleidoscopio/article/view/23899/22301. Acesso em: 23 mar. 2019.

QUADROS, R. M. Situando as diferenças implicadas na educação de surdos: inclusão/exclusão. Ponto de Vista, v. 5, p. 81-11, 2003. Disponível em: https://periodicos.ufsc.br/index.php/pontodevista/article/viewFile/1246/3850. Acesso em: 23 mar. 2020.

SACKS, O. Vendo vozes: uma jornada pelo mundo dos surdos. Rio de Janeiro: Imago, 1989.

SACKS, O. Vendo vozes: uma viagem ao mundo dos surdos. Trad. Laura Teixeira Motta. São Paulo: Companhia das Letras, 2010.

SERRA, D. Inclusão e ambiente escolar. In: SANTOS, M. P.; MOREIRA, M. (Org.). Inclusão em educação: culturas, políticas e práticas. São Paulo: Cortez, 2006.

SOFIATO, C. G. Ontem e hoje: o uso de imagens na educação de surdos. Journal of Research in Special Educational Needs, v. 16. n. s1, p. 789-794, 2016. 